\title{
The Phenomenological Interpretation of Creation of the World out of Nothing: from Patristics to Kant and Beyond
}

\author{
Alexei V. Nesteruk ${ }^{a *}$ and Tatiana V. Litvin ${ }^{b, c}$ \\ ${ }^{a}$ University of Portsmouth \\ Lion Gate Building, Portsmouth, PO1 3HF, UK \\ ${ }^{b}$ National Hellenic Scientific Foundation \\ 38 Vassileos Constantinou, Athens, 11635, Greece \\ ${ }^{c}$ Russian Christian Academy for Humanities \\ 15 nab. Fontanka, St. Petersburg, 191011, Russia
}

Received 09.08.2018, received in revised form 23.08.2018, accepted 06.09.2018

It is argued that any approach to creation of the world out of nothing in the natural attitude is impossible. Correspondingly creation escapes the limits of metaphysics and can be presented in the phenomenality of events. The paper deals with some arguments of the Church Fathers in opposition to those who denied creation out of nothing on the basis of the argument "Why not sooner?" It is demonstrated that the Fathers' analysis anticipated the modern view that the creation of the world can only be treated in the event-like phenomenality thus forming a saturated phenomenon. Then we carry out the analysis of Kant's first cosmological antinomy with the aim to confirm our thesis that the origin of the world cannot be presented in the phenomenality of objects. In conclusion we formulate a thesis that the universe as a whole, as well as its origin can only be comprehended as event unpredictable and irreproducible, exceeding all cause and making the impossible possible, surpassing all expectations and predictions.

Keywords: cosmology, creation, Christianity, event, ontology, phenomenality, philosophy, patristic theology, time.

Research area: philosophy.

Citation: Nesteruk, A.V., Litvin, T.V. (2018). The phenomenological interpretation of creation of the world out of nothing: from patristics to Kant and beyond. J. Sib. Fed. Univ. Humanit. soc. sci., 11(10), 1604-1634. DOI: 10.17516/1997-1370-0324.

(c) Siberian Federal University. All rights reserved

* Corresponding author E-mail address: alexei.nesteruk@port.ac.uk

This work is licensed under a Creative Commons Attribution-NonCommercial 4.0 International License (CC BY-NC 4.0). 


\section{Introduction}

One of the major elements of the Christian teaching is the affirmation that the world was created by God out of nothing. The Fathers of the Church attempted for centuries to elucidate the sense of this dogma in philosophical terms, in particular by dealing with the temporal dimension of creatio ex nihilo. On the one hand the creation of the world is represented through the unfolding changes of the world, on the other hand such a thinking is problematic, because the very representation of creation out of nothing takes place in the already existing form of created subjectivity. Thus, as it was asserted before, any representation of creation in the natural attitude is problematic (Nesteruk, 2014; 2015: 414-416). Indeed Christian cosmology, having been imbued with the Greek philosophy originating from pre-Christian times, had inherited the picture of the physical world based in the Aristotelean philosophy and Ptolemy's ( $2^{\text {nd }}$ century BC) astronomy in which the cosmos was presented by a system of the heavenly spheres, bearing the moon, five planets and the sun, rotating around their geometrical and ontological, immovable centre with the earth. The cosmos was finite and concluded by the sphere of immovable stars, a "boundary of the universe", beyond which was a mysterious nowhere. Saying differently, the cosmos of Christians, in spite of not being their home (St Augustine), was an object of a passive contemplation, sometimes detached from its perception as a good creation by good God. At the same time the Fathers of the Church were not concerned too much with knowledge of the world per se and cosmos did not have the same importance for them as it was for the pagan philosophers. Correspondingly, when one invokes the term "cosmology", "cosmos", "cosmic vision", "Christocentric cosmology" etc., reflecting the often claimed "cosmic dimension" of Patristic theology, these cosmic connotations are not those which were meant by the ancient Greek philosophers (and certainly not by modern physical cosmology). One could suggest, hypothetically, that the Fathers could have been interested in reconciling the ancient Greek cosmology with that of the Genesis of the Bible (which does not have any indication of the spherically structured universe). One can add to this that the perception of the finitude of the spatial dimensions of the natural world following from Ptolemaic cosmology must have been complemented by the perception of the finitude in duration of the world that followed from Biblical teaching. However, this cosmographic, or, so to speak, natural finitude was inherent in Fathers' thought not only because of astronomical ideas and Biblical tradition; for them space and time were finite first of all on the grounds of their epistemological understanding as expressions of finitude and limitations in general. For example, temporality is a characteristic 
of the finite creation related to all things. According to Maximus the Confessor, for example, "...everything is certainly in time, since everything that possesses existence after God possesses this existence in a certain way and not simply. And therefore they are not without beginning. For if we know how something is, we may know that it is, but not that it [always] was." Here is the motive of creation is present: the universe cannot be infinite in time and space because it was created out of nothing, so that its hypothetical infinitude would contradict its created nature. In this sense the notions of infinite space and endless time are contradictory as being a mixture of that which is supposed be uncreated (the infinite) and created (which is always given in rubrics of limited spatiality and limited movement (temporality)).

However this part of cosmology of the Fathers, as being concerned with the visible creation did not deal with the issue of creation out of nothing proper. The major problem was the explication of the sense of creatio ex nihilo in philosophical and theological terms. Most of the Fathers, Maximus the Confessor, for example, attempted to represent creation through its constitution, for example, as the distinction and difference (diaphora) between the visible and invisible (sensible and intelligible) realm in creation. Such a cosmology is realistic in the sense that it does not enquire into the conditions of the possibility of the constitution the world by the human subject. In other words, the natural attitude ${ }^{2}$ is used in speaking about creation. But this approach is fundamentally problematic for one cannot position "creation of the world" outwardly as if the enquiring consciousness would be positioned outside creation. Expressing the same idea differently, the problem is to attempt to find a pre-existing ontological context in which creation would be a sort of an anticipated effect. Such a context does not exist outside creation that entails that ontological categories do not suit any description of creation out of nothing. Classical metaphysical context and ontology thus must be abandoned, abandoning together with it the natural attitude and any representation

\footnotetext{
Maximus the Confessor, Ambigua 10, PG 91, 1180 C-D [This ET: (Louth, 1996: 139)].

The natural attitude is related to the activity of consciousness and, according to M. Natanson: "Within the natural attitude I act in a world which is real, a world that existed before I was born and which I think will continue to exist after I die. This world is inhabited not only by me, but also by my fellow men, who are human beings with whom I can and do communicate meaningfully. This world has familiar features which have been systematically described through the genetic-causal categories of science. The world of daily life is lived within this natural attitude, and as long as things go along smoothly and reasonably well, there arises no need to call this attitude into question." The reasonability and wellness is related to the situation when the question about the contingent facticity of that which is going on around, including the facticity of the whole world and the "I", which makes enquiries about it, does not arise. Then Natanson continues: "But even if I do occasionally ask whether some things "really real", whether the world is "really" as it appears to be, these questions are still posed in such a way that they are my questions about the natural world in which I live. I do not really scrutinize my natural attitude in any rigorous manner: I merely mark off a bit of it for more careful study" (Natanson, 1959: 232).
} 
of creation out of nothing in the phenomenality of objects. As we will see below the situation is similar to the futility of describing the event of birth of man in the limits of ontology or phenomenality of objects. In the same way as life through its coming into existence is accepted in theology as that primary givenness in the human Divine image which cannot be denied, creation cannot be denied, it cannot be bracketed (as the bracketing of the world) and thus cannot acquire the phenomenality of objects. ${ }^{1}$ Saying differently, one cannot approach the issue of creation in the phenomenality of objects which requires the pre-existent temporal context.

Indeed, it is intuitively clear that creation is a unique happening which exceeds any anticipation in terms of quantity, quality, modality and relation. As was argued elsewhere one can speak of creation as a saturated phenomenon (Nesteruk, 2015: 403474), implying that the only plausible way of treatment of creation out of nothing is to consider it in the phenomenality of events. The philosophers of antiquity and Church Fathers anticipated this predicament of dealing with creation and attempted to tackle it by using those philosophical means which have been available to them. Can these means be interpreted in a new way in order to give a more articulate explication of the thesis that creation out of nothing escapes ontological description and represents an eventlike phenomenon, saturating intuition by its content and linking its phenomenality to that one of the self-affectivity of life, experiencing itself from itself, that is being the revelation of life to itself that is the revelation of God? In order deal with such questions we consider one of the remarkable arguments used by the Church Fathers in order to affirm the truth of creation out of nothing (escaping any anticipatory context) that was developed in the course of the opposition to the idea of creation based on the argument known under the name of "Why not sooner?"

If creation of the world did take place in the finite past of the world, assuming that one can have either a theological or physical estimate of its age, the argument against such an assertion runs as follows: why did the world was created not before or later than those thousands of years which were allocated to the age of the world on the basis of the Bible reading (billions of years in modern scientific terms, on the

\footnotetext{
It is the inseparability of the universe and a subject, observing it from within that makes the cosmological idea (that is the idea of totality of the world) fundamentally different among other ideas of reason, such as the idea of soul or the idea of God. Kant wrote that neither psychological nor theological idea entail contradiction and contain antinomies (Kant, A673/B701, 1933: 552). Practically this means that one can easily deny the existence of a soul (let us say, on materialistic grounds) or deny the existence of God (on atheistic grounds). However it is impossible to deny the existence of the universe for it would deny the empirical world of sense which is part of the universe and which contains the foundation of all knowledge about universe.

2 See a comprehensive review in (Sorabji, 1983: 232-238).
} 
basis of cosmological observations). As we will see below, the strong refutation of this argument was based on a philosophical observation that it was no time before creation, so that the question "Why not sooner?" does not have any sense if it is treated in terms of temporal sequences. Another line of argument was strictly theological and appealed to the incomprehensible nature of God, whose volition of creation is beyond human wisdom. What is interesting from our point of view is that all assertions on creatio ex nihilo, with the impossibility to position it as some happening in terms of time and space, de facto, refute, in a modern language, the employment of the natural attitude, or phenomenality of objects for tackling the issue. This brings an opportunity to elucidate and may be develop a view of the creation out of nothing in the phenomenology of events, treating creatio ex nihilo as an event of the impossible, beyond quantification and qualitative definition, beyond modality and relationality, the inaugural event donating thus an unpredictable and unforeseeable future to the universe. The defence of the idea of creation by the ancient philosophers and the Fathers, being treated phenomenologically, represents an interest for phenomenology of events, as well as for theology, mutually fertilising each other and elucidating further the human capacity of dealing with such saturated phenomena as creatio ex nihilo.

\section{Creatio ex nihilo in Patristic Thought: Reification by Augustine and Maximus the Confessor}

There is no need to repeat at length about Christian teaching on creation of the world created God out of nothing. Basil the Great, in his Hexaemeron made a distinction between creation of the intelligible world with no temporal flux and no spatial dimension, and the creation of the visible universe together with "the succession of time, for ever passing on and passing away and never stopping in its course" (Basil the Great, I:5, 1994: 54). Basil asserts that the meaning of the Biblical phrase "In the beginning God created" must be understood as "in the beginning of time" (Basil the Great, I:5, 1994: 55), that is God created the visible world together with time, and it was the beginning of time in the visible world ${ }^{1}$. In order to articulate the a-temporal nature of "the beginning of the world", and to remove any causation at the beginning in terms of time-series, Basil affirms that "the beginning, in effect, is indivisible and instantaneous...the beginning of time is not yet time and not even the least particle of it" (Basil the Great, I:5, 1994: 55). Augustine in Confessions, XI addressed the problem 
of the origin of time directly, affirming similarly to Basil, that: "The way, God, in which you made heaven and earth was not that you made them either in heaven or on earth... Nor did you make the universe within the framework of the universe. There was nowhere for it to be made before it was brought into existence"1; the universe was not created by God in time, but was created with time ${ }^{2}$. Augustine affirmed the creation of the universe and time within it as the only consistent expression of the Christian affirmation of creatio ex nihilo. The nihilo could not be something, it could not have any attributes of created things, it must be an absolute philosophical no-thing.

Maximus the Confessor, following his predecessors, repeats that the world was created out of nothing because of God's will and goodness, by his Wisdom and Logos. The createdness of the word implies its non-eternity and consequently its beginning in time. However, in spite of that the beginning in time can be understood only from within the already created (according to Augustine this cannot be a "beginning" as if it would be seen outside the world), Maximus points to a difficulty that can arise. One reads a passage from his Centuries on Charity 4.3: "God, who is eternally Creator, creates when He wills by His consubstantial Word and Spirit, because of His infinite goodness." This is a general statement which does not raise any questions because this is a matter of religious conviction. Then Maximus anticipates a possible question on details of this creation of the world: "Nor must you object: Why did He create at a certain time since He was always good?" Here the question is formulated from within those categories of sequence and time which pertain to the already created world. Indeed, if the creation of the world happened several thousand years ago measured by the created time, why this age of the world is such as it is; in other words, can we enquire into the nature of this age's contingent facticity as it is contemplated from within creation? Maximus gives a characteristic response - "no": "The unsearchable wisdom of the infinite essence does not fall under human knowledge." It is impossible to transcend the boundaries of the created and to enquire into its facticity on the grounds of the impossibility of knowing the divine volitions and intentions; creation with its scecific and contingent features remains a divine mystery connected with the divine providence.

Here it is interesting to note that Augustine was essentially concerned with the same question as Maximus later. In his Confessions, Augustine, enquired, from the

Augustine, Confessions, Book XI:5. [This ET: (Chadwick, 1991: 225)].

Augustine, City of God, XI:6.

This ET: Sherwood P., St. Maximus the Confessor. The Ascetic Life. The Four Centuries on Charity (London: Longmans, 1955), p. 192. 
name of an anonymous converser, on why creation is not eternal: "But if it was God's everlasting will that the created order exist, why is not the creation also everlasting?"1 One can grasp that this question of Augustine is equivalent to the question of Maximus the Confessor on why creation now and not later by appealing to another text of Augustine from "The City of God" where he discusses another question on why the first creation of man happened later than before. Augustine reacts to the question "why an infinity of ages passed without man's being created, why his creation was so late that less that six thousands years, according to scriptural evidence, have passed since he first came into existence" by making a reference that any finite period of created time, be it six thousands or six millions years is incommensurable with the Divine eternity, and thus the questions as to why now, that is late, and not before, has no sense in the perspective of eternity. Augustine reduces this question to the problem of the contingent facticity of creation of man in general: "Therefore the question which we now ask after five thousands years or more, posterity could as well as, with the same curiosity, after six hundred thousand years, if the mortal state of humanity, with its succession of birth and death, should last so long... In fact the first man himself might have asked, on the day after he was made, or even on the very day of its creation, why ha had not been made sooner. And whenever he had been made, no matter how much earlier, this objection about the beginning of temporal things would have had precisely the same force then as now-or at any time" ${ }^{2}$

In modern context the passage quoted above is interesting by that that it explicates the problem of the phenomenological concealment of both a birth (or conception) of man, as well as creation of the world as a whole. Augustine points out that the concealment of both events is associated with the incommensurability of the finite and limited created on the one hand, and that ontologically other foundation of the hypostatic life and the world, which can be characterized as non-original beginning, as that immemorial without which one cannot have a temporal perception of the world and which nevertheless escapes all definitions in terms of this world. In its essence, since the concept of creation out of nothing excludes any causal foundation of the world, creation of the world and man are both contingent events with respect to which any question of their "earlier" or "later" has no sense. ${ }^{3}$

Conf. XI, 10 [ET: (Chadwick, 1991: 225)].

Civ. Dei., Book XII. 13 [ET: (Bettenson, 1980: 486-487)].

The analogy between the phenomenological concealment of creation of the world and of man's birth was discussed in my article (Nesteruk, 2012: 172-205), as well as in (Nesteruk, 2015: 305-347). 
However, one must analyse further some implications of the question, discussed by Maximus. If the question about "when" of creation is related to the temporal span of the physical universe seen from within this universe then one can find parallels with contemporary cosmology. Formally, Maximus' question can be translated by using modern cosmological language into a question about the initial conditions of the universe which fix its physical parameters, including its age. But physical cosmology cannot give an account of the initial conditions for the dynamical laws which drive matter and space of the universe. Correspondingly cosmology cannot provide a clear explanation why the age of the visible universe is about 13.7 billion years. Since we can speculate on the nature of the initial conditions only from within our universe by extrapolating backward the properties of the observable universe, the 'knowledge' of the initial conditions thus achieved does not tell us anything about these conditions, as if there were special trans-worldly physical laws responsible for these conditions as the outcomes of these laws. ${ }^{1}$ Being bounded by the universe one cannot know the "laws" of the initial conditions of the universe as if they could be attested from beyond the universe (we can only postulate them). It is in this sense that Maximus' response "no" to knowledge of the "initial conditions" of the created universe (that is "Why not sooner or later?" exactly corresponds to "no" in knowledge of scientific cosmology of the initial conditions which fix the contingent facticity of the universe and its internal age.

Nevertheless, to explicate the sense of Maximus's question about "when" of creation and his negative reaction to it, one can be reformulate this question as if the universe appeared out of something preexistent. This is done purely of pedagogical purposes by understanding that, if one treats creation out of nothing consistently, nothing can pre-exist it. Still, let us imagine a pre-existent space-time continuum in which our universe appears (in its visible form) at some of its "moment" and "location". Then the question "when" of creation will have another sense, if it is addressed from the outside of the universe, as a particular "when" in pre-existent time. For a moment we skip any concern about the sense of this preexistence, that is whether it is related to the multiverse, or something "before" the Big Bang, or to a cycling universe of Penrose's type. ${ }^{2}$ What interests us is a possibility to approach the act of creation as an

1 A famous example of such a hypothetical law is R. Penrose's hypothesis postulating the low gravitational entropy in the beginning of the universe. See (Penrose, 2005: 726-732; 765-768).

2 Multiverse represents a theoretical notion reminiscent to the perennial idea of plurality of worlds. In modern cosmology this notion has different physical and mathematical interpretations starting with the ensemble of the different physical universes disjoint in space and finishing by the variety of all mathematically possible worlds 
"object", that is as a causal transition from something "before" to that which is here and now. This would be typical for the natural attitude to "look at" the creation and ask a question on the specificity of this or that "moment" of its happening in the preexistent scheme of things. Certainly one could refer to Augustine's ways of responding to such a question simply pointing to the fact that "before" the world was created no entities such as all-embracing space or time could exist. Such an Augustinian response is true in its philosophical essence, but it would be useful to confirm this truth through a negative assessment of modern models of creation with preexistent space-time. Indeed to ask why creation "now" but not later or before, would imply the possibility of approaching the creation within the anticipatory space-time concept, that is to position it as a "physical event", as a particular happening in the series of causations of causations allegedly existing outside the universe. ${ }^{1}$

As an example of "creation" in preexistent space time there is a model of "creation" of matter in the universe (not space and time) from the initial state with the total energy of matter equal zero (imitating nothing). ${ }^{2}$ The major feature of this model is that the universe originates in pre-existent space and time as a result of a fluctuation in the physical vacuum (a physical state of matter in which the values of all observables of particles are zero). Geometrically the development of such a universe can be presented as a future light cone, whose apex is positioned arbitrarily in pre-existent space and time. It is exactly this arbitrariness of the "place" and "moment" of origination of the visible universe, which constitutes a difficulty similar to that of Maximus: it is impossible to specify and justify why the universe originated at a specific point of space and time (that is it is impossible to specify "when" of this origination): the spontaneous "creation" of the universe could occur anywhere and at any moment of pre-existent space and time. In fact, a variety of different universes could originate at different locations of the preexistent space-time, driving cosmology to face a serious problem of the mutual influence of different universes.

Correspondingly the question of "when" of "creation" not only cannot be answered, but, in fact, does not have any sense, for if the preexistent space-time is infinite, an

in a platonic sense. Some physicists advocate the relevance of the theory of the multiverse to physics, some other claim that this notion has a philosophical standing and is not physical. (See, e.g. (Carr, 2007)).

1 This logic is, in a way, inverse with respect to what, in history of discussions on extracosmic space, was called "intrusion" arguments. The essence of these arguments is that is the cosmos in its entirety will decay through fire, there must be extra space for that conflagration. A similar argument for extraspace was historically produced by Cleomedes in his hypothesis of the possibility of the whole cosmos to be shifted. If this were to be possible, there must be extracosmic void. See details in (Sorabji, 1988: 125-141).

2 See (Tryon, 1998: 222-225). 
infinite time could have passed since our universe originated. But this makes the question of temporality of the moment of creation devoid of any meaning. ${ }^{1}$ Similarly the question of a spatial location of such an origin in pre-existent space does not have any sense. ${ }^{2}$ There is no need to argue that this kind of model has nothing to do with creation out of nothing in a theological sense, for space, time, the meta-law, and the quantum vacuum are all assumed to be pre-existent. It is reasonable to talk about the temporal origination of the material universe rather than about its creation out of nothing. ${ }^{3}$

The beginning of the world and its created temporality can be grasped from within the world, so that this beginning is the constituted beginning from within the world. No constitution or objectivisation of this beginning is possible from beyond the world, because this "beyond the world" is not an "object" but rather the condition of the very possibility for the world to be manifested to and articulated by human beings. In this sense the quest for the beginning of the created universe reveals itself as a quest for the limits of human consciousness attempting to grasp the facticity of the world.

What is interesting is that the refutation of models of "creation" of the universe in preexistent space-time leads us to further clarification of what is meant by creation in theology. Indeed, the logical difficulty of models with pre-existent space and time is connected with the inability to locate the moment of time and place in space where the universe originated, from outside, by transcending beyond the universe itself, into its imaginable preexistent "before". One can argue about the beginning of time within the visible universe by extrapolating its expansion backward in time. But this will never allow one to claim scientifically that there either was or was not pre-existent

1 By an analogy with the abovementioned reference to St Augustine, the universe emerging from the vacuum fluctuation is incommensurable with the totality of the infinite pre-existent space and time, so that its positioning in the infinite space time does not have any sense.

2 One can invoke a famous Aristotelian objection to existence of a void beyond the cosmos on the grounds of the counter arguments to Cleomedes who suggested that the whole cosmos could be shifted as a whole. According to Aristotle the logical difficulty would be exactly in the choice of the direction of movement: why should the cosmos move in this direction rather than that, and why should it stop here rather than there? (Aristotle, Physics, $4.8,215 \mathrm{a} 1)$. In modern terms this can be described as if the preexistent space would be uniform: the uniformity makes devoid of any sense questioning the absolute position of the cosmos since all locations are equivalent, so that the location of he cosmos could be described in terms of "everywhere" and "nowhere".

3 It is interesting to note that the first 'scientific' ideas on the origination of the universe in pre-existent space and time were proposed by Newton who intended to reconcile the Biblical account of creation, where the world had to have a beginning, with his view that time could have neither beginning nor end. Newton asserted that the visible universe was brought into existence by God in the past which is separated from us by finite time, but this took place within the absolute and infinite space and time. The creation of matter in Newton's model is detached from the creation of time. One sees here a fundamental difference not only with the contemporary views based on General Relativity, where space and time are relational upon matter but even with Maximus the Confessor for whom space and time where inseparable elements of the creaturely nature of the world (Balthasar, 2003: 139). 
time "before" our universe came into existence. The situation was described by Kant in terms of his first cosmological antinomy as a logical tension between the thesis, that the world has a beginning in time and is also limited as regards space, and the antithesis, that the world has no beginning and no limits in space; it is infinite as regards both time and space (Kant, A 426-427/B454-455).

The abovementioned antinomy which arises in cosmology with pre-existent space and time can be considered from a different perspective, without any reference to space and time, which brings us even closer to the thought of Maximus the Confessor on the illegitimate interrogation about "when" of creation. For example, the thesis can be treated as the affirmation that the visible universe is unique and finite as regards space and time, whereas the antithesis is that the visible universe, being finite in terms of its temporal past, is one particular representative out of the ensemble of universes with different boundary conditions (corresponding, in the previous logic, to different moments of their origination in preexistent time). The plurality of different boundary conditions corresponds to the logical multitude of a Platonic-like kind, so that the antinomial nature of any predication on the uniqueness or not of these conditions becomes evident because the ontological status of that which is predicated in thesis and antithesis is different: one can make an empirical inference with respect to the visible universe, whereas an assumption that there is an ensemble of universes, which one cannot verify empirically, requires an intellectual inference, that is the reference to the realm of the intelligible. In this case the whole meaning of the antinomy reveals itself as predication about two ontologically distinct realities, that is the empirical visible universe and the Platonic-like ensemble of the universes. If we extrapolate this reasoning back to the problem, discussed by Maximus the Confessor, the question posed by him in the Centuries on Charity 4.3 must be transformed in such a way that the temporal aspect of the specificity of the creation of the world is replaced by the aspect of "choice" of this particular world out of many potential possible worlds, namely "Why did God choose to create this world but not the other?"

It is not difficult to see that in this theological extension of the idea of pre-existent space and time towards an intelligible realm one abandons an ontological insight on the nature of appearance of the visible universe (thus removing metaphysical reasoning) and replaces it by an "event-like" argument, related to the Divine agency. This implied

\footnotetext{
In modern cosmology such an interpretation corresponds to different models of the multiverse. It has also particular connotations with Penrose's suggestion that the special initial conditions of our universe responsible for arrow of time in it, are set up from outside through choosing them out of many other possibilities, which could lead to different universes. See (Penrose, 2005: 726-732).
} 
event has nothing to do with the causality of the world because it has the transcendent foundation. Correspondingly it has the sense of the inaugural event, granting the universe the future, but whose literal sense can only be disclosed through the movement of thought in the thus "chosen" universe. Certainly the imagery of the ensemble of the universe as they stand in front of the "mind of God" is itself a metaphor made in the natural attitude assuming that one can position these universes as the outside entities. However their status remains that of intelligible objects pressing again the point that these universes remain created entities and one cannot separate them from that subject who asserts the free choice of God in materialising the universe with those initial conditions which lead to the observable display of the cosmos. The appeal to the "choice" of the initial conditions effectively points to the freedom and wisdom of creation of the world with no reference to the anticipatory context of such a creation if the latter could be imagined. Correspondingly, for us this "choice" carries the traces of an event exceeding the measure of the metaphysically possible, unpredictable and unforeseeable.

Since in the times of Maximus, phenomenology of events did not exist, his vision of the issue we are concerned with was shaped differently, but in its spirit similarly, by transforming the ontological question of "Why not sooner?" into the question of an event in the internal life of God.

\section{The Origin of the Universe and the logoi of Creation}

In Ambigua 7 Maximus states that "the logoi of all things known by God before their creation are securely fixed in God.... Yet all these things, things present and things to come, have not been brought into being contemporaneously with their being known by God; rather each was created in appropriate way according to its logos at the proper time according to the wisdom of the maker...." He makes a distinction between knowledge of things by God in their logoi and their actual coming into being. Knowledge of things even if they are known eternally does not imply the necessity of their existence as created. There is an ontological incommensurability between things known by God as potentially existent and those which were brought into being. If one applies this thought to the universe as a whole, one can suggest that the knowledge by God of this universe with a potential to become created does not necessarily imply its creation. There is a gap in the necessitation between knowledge and actual creation

Ambigiua 7, PG 91, 1081A. [This ET: (Blowers, Wilken, 2003: 56-57)]. 
which is based, according to Maximus, in the Divine wisdom and will and which not only brings all things into existence at their proper time, but ultimately brings the actually existing world as a whole into existence. The words of Maximus related to the wisdom of the Creator with regard to the "determination" of a proper moment of creation can be, by a matter of philosophical suggestion, applied to the "determination of the choice" of the world as such, or, in cosmological phraseology, the choice of the world with those boundary conditions which led to the actual display of the universe. Then the question is: "Could God know not only of this world which he has actually created, but other potential worlds which either have not been created at all, or have been created in a different mode of being?" If the answer is yes, then we must suppose that just as God applied his wisdom for creating this world, he must have been wise of not creating other worlds, or creating them in a different mode of being. This wisdom reveals itself through God's will to make a choice in the actual creation of this world. Correspondingly all other worlds, being only potential possibilities either remained as such, or they were implanted in creation, for example, as intelligible entities with the logoi not to acquire any corporeal shape, remaining the images and prints of the divine wisdom accessible to an intellectual search and contemplation. In this sense the very idea of the variety of the "boundary" conditions for the created world manifests itself as a pointer, a paradeigmata, towards the detection of the divine wisdom. If our way of extrapolating Maximus' thought is correct, then it relieves us from the uncertainty of creation related to the allegedly preexistent choice of the possible worlds with different boundary conditions and makes the problem of the specific temporal beginning (as special boundary conditions) of our universe to be transformed toward the problem of the special ontological distinction, or extension (diastema) between God and the world. This transformation allows one to look at the distinction between God and the universe (that is between uncreated and created) in terms of a definite structure in creation, namely in terms of the difference between that world which has its corporeal representation and those potential worlds which do not have such a representation remaining no more then intelligible traces of that which could be known by God, but not created in the corporeal form. The actual choice of creating our universe is thus a setting up a special difference in creation between intelligible (created non-corporeal worlds) and sensible (our actual world). In this case the setting of the boundary conditions for the actual physical universe, as a corporeal choice out of many possible universes, implies that these boundary conditions, or the origin of the physical universe, presuppose a definite structure of the intelligible realm which complements the actual 
universe in the whole creation. In different words, the choice of the corporeal world out of many potential worlds means setting up the basic ontological difference (the basic diaphora) in creation, which thus becomes a constitutive element of creatio ex nihilo. ${ }^{1}$ The will and wisdom of God in creating this world with its particular immanent age (which is the subject of Maximus' discussion) is thus encapsulated in the specific diaphora between this world and all those which are not destined to become corporeal. And it is this last sentence that unfolds to some extent the sense of the logos of creation of our universe.

Coming back to the initial stance of Maximus on creation, one could suggest that his ultimate objective was to provide a logical and philosophical argument that the world had a beginning in the sense that it is not eternal and hence incommensurable with God. The fact that the world's parts are subject to temporal flux and decay is part of the mundane experience. The question of the temporality and decay of the world as a whole is much more problematic. Everything depends on how this wholeness is understood: if it is just an additive something comprised of the parts, then the criteria of the finitude and created temporality can be applied to the world as well. However there is a difficulty, which is well understood in modern cosmology, that one cannot speak about the universe as a whole as being in space and time and hence as subject to the same constitutional synthesis which is applied to separate physical objects. In this sense the universe as a whole is not in space and time and that is why it is unclear how one can contrapose the whole universe to the Divine eternity and what kind of incommensurability is implied here. The logical inconsistency of applying such notions as space and time to the universe as a whole, does not remove, however, the fact that the universe is created and its contingency requires a sufficient foundation. If this universe as a whole is not eternal (in terms of immanent time), then it has "transcendent beginning" which rather implies a logical origination, or dependence upon something which is absolutely necessary. Even if cosmology would pronounce that the world is eternal as evolving indefinitely in terms of the immanent time, this eternity as an endless temporal flux has a different ontological status in comparison with the transworldly eternity understood as absolutely necessary being.

The important conclusion from this discussion is that modern cosmology, in spite of all its attempts to predicate the initial state of the universe through the theories of the Big Bang, comes to the same conclusion that was grasped long before by the Fathers,

\footnotetext{
See details in (Thunberg, 1995: 50-55).
} 
namely that the "original" state of the universe which symbolises its unity, identity and totality cannot be defined in immanent terms; it requires a founding principle which explicates the logos of creation of the universe, the principle which can be formulated in Maximus' words as "the whole of creation admits of one and the same undiscriminated logos, as having not been before it is"1, or, "the divine principle which holds the entire creation together is that it should have non-being as the ground of its being." ${ }^{2}$ This helps to give the discursive explanation of what it means to detect the presence of the logos of creation from within the created realm: namely to establish the understanding that every created object, intelligible or sensible, is theogenically uniform, that is it has one and the same transcendent ground of its existence in its non-existence (non-being), or, in different words, in its otherness. It is this theogenic uniformity which cascades, in cosmology, to the cosmographic uniformity.

Modern cosmology is unanimous in that the Big Bang was an event in the past which is extraordinary and antecedently efficacious with respect to all possible events that happened in the universe since then. This exceptional event, predicted theoretically and having some observational consequences tests the limits of the physical sciences. That physics which has been discovered on the planet earth in a relatively short historical period can be applied only up to this boundary in the past of the universe beyond which any scientific claim is problematic. In spite of the obvious fact that there is no evidence for claiming that this event can be associated with creatio ex nihilo, its theoretical prediction at least sheds the light on some constitutive elements of creatio ex nihilo, which explicate the logos of creation of the universe. We intentionally avoid any talk about the "explanation" of the creation of the universe out of nothing; instead we speak of the detection of the presence of the logos of creation, the logos of that originary state in the universe with respect to which human comprehension experiences an imminent difficulty. The detection of the presence of such a logos, being an event in the spiritual life of a believer cascades to the comprehension that the creation of the world out of nothing is a saturated phenomenon, confrontation with which indicated the commensurability of creation with an event of life thus making creation itself a part of the event of life confirming a longstanding thesis of the Christian cosmology that it is human history which determines the cosmic history, but not vice versa (Clément, 1976: 80).

\footnotetext{
Ambigua 41, PG 91, 1312B [This ET: (Louth, 1996: 160)].
(Thunberg, 1995: 401). C.f. Maximus the Confessor, Centuries on Charity 3.28: "We affirm that the divine substance alone has nothing contrary, since its is eternal and infinite and bestows eternity on all the rest. The substance of things, however, has not-being as contrary" [This ET: (Sherwood, 1955: 178)].




\section{"Why not sooner?" and Kantian cosmological antinomy}

We have already seen that the problem "Why not sooner?" is closely connected with the Kantian cosmological (mathematical) antinomy about the origin of the world. The analysis of this antinomy confirms with an even greater force that the natural attitude is non applicable to the issue of creation of the world and this analysis contributes to the explication of creation of the world as an event.

According to Kant, the First Antinomy is formulated, as the opposition between the thesis that the world had a beginning in time and is limited in space, and antithesis that it had no beginning in time and is unlimited in space, being infinite in its duration backwards and in its extent (Kant A426-427/B454-455). Kant claims that he refutes both thesis and antithesis, assuming that a refutation of the either would be an indirect proof of the opposite. For the purposes of our research we mostly concentrate on the refutation of the thesis, placing Kant's way of thought in line with those objections to creatio ex nihilo which have been already considered and originating from the argument "why not sooner?"

If the world had a beginning this would imply the existence of "empty" time before the world began. Then he argues, similarly to Augustine and Leibniz, that there is nothing in any moment of "empty" time to determine why the world had begun at that moment rather that at any other. Correspondingly, referring to the Leibniz's Principle of Sufficient Reason and pointing that there were not sufficient reason for the world to begin at one or another moment of "empty" time, it cannot begin at any moment of this time and hence it never began. Seen from the perspective of the present, this refutation of the thesis can be compared with the argument "why not sooner?": indeed, the inability to position the beginning of the world in pre-existent "empty" time is equivalent to the question as to why the world has begun at certain moment in the past, but not sooner (or later) with respect to the present. The refutation of Kant's thesis has as a premise the idea of absolute space as it was promoted by Newton. Correspondingly the refutation of the thesis proposed by Kant implies first the acceptance of the Newtonian vision of space. This means that if the Newtonian substantive representation of space and time is not shared by some philosophers, like Leibniz, for example, the whole power of the refutation immediately collapses by saying that the initial idea of empty time is inadequate. One notices here a certain reference to the previously discussed arguments of Basil the Great and Augustine that no time was in existence before the world has begun. Similarly, if according to Leibniz's model of relational space there must have been an inaugural event of relation between things in the world which gave rise to space 
and time, then the problem of the beginning of time can be reformulated as existence of an inaugural event such that it was followed by other events but was not preceded by any other events. The inaugural event would not mean an event in an ordinary sense as if it happened in the background of the already existent time. This event would be the generating state of affairs from which all consequent events (or instants of time) unfold. In this case the parlance of empty time "before" this first event would loose its sense and the whole acuteness of Kant's thesis would transform into the question of the first (inaugural) event. In other words, the assertion of the thesis on the beginning of the world in time would transform into the assertion of the first event and the issue would become as to "Why did the particular event with no antecedent causation took place?", or "Why such an event does not have predecessors at all?", or "Why such an event happened in order to launch the coming of the world into existence?" Since Kant does no appeal, in a style of the Church Fathers to the argument of God's will, wisdom and love, he does not consider his refutation of the thesis as a possible objection to creatio ex nihilo. He remains in a philosophical frame of mind and in many ways is concerned with the explication of the difficulties of the human mind in tackling the questions about infinity and ultimate reality. However, seen through a theologically committed insight, one understands that the limits of the understanding originate in the conditions after the Fall, resembling the moral tensions in representation of things seen as objects or as events. It is in this perspective one can look at Kant's antinomy as a vivid explication of the tension in representing the world in the phenomenality of objects or events. If his appeal to empty time effectively positions the world as and object in pre-existent space and time of a Newtonian kind - we have a problem of understanding the beginning of the world. If, on the other hand the same thesis is understood as a statement on the inaugural first event, then one understands that the refutation of Kant does not have sense, for the inaugural event enters human consciousness as a saturated phenomenon whose constitution within the transcendental limits is not possible. Hence its refutation is impossible. Correspondingly the very sense of the antinomy changes: it just says that one cannot deal with the beginning of the world (or its spatial boundaries) in the natural attitude.

If in a historical approach to the question of the beginning of the world as ("Why not sooner?") the main focus was on the positioning of the inaugural event associated with the creation in the finite past and enquiring about the contingent measure of the temporal span to this event from the present, in Kant's perception this issue is interpreted "outwardly" by positioning the inaugural event as an "ordinary" happening 
in the background of the pre- existing "empty time" which, by construction is not subject to any limiting definition and thus is infinite in a vague sense. What happens here is that the very beginning of the world is considered as part of the logic in which the world pre-exists this event. Hence the issue of its arbitrariness emerges. However in its essence the event of the beginning of the world cannot be by its nature described as a mundane happening in pre-existing time. Correspondingly any attempt to assign to it any temporal setting in terms of its own beyond and in the quality of either infinite or finite time does not have sense. What happens in Kant's refutation of the thesis of the antinomy is that the question of the inaugural event is not distinguished from the question of the infinite or finite duration of the world. In other words, it is not clarified carefully whether the implied temporality is related to the world which has already emerged from the inaugural event or this temporality has a general property of being independent of the fact of the existence of this world.

If there was a first event in the world's history, then the duration of that history backwards from any assigned instant in it, for example the present, is finite. This is true in the case if this first event can be identified as that one which did not have predecessors. However the sense of the finitude of the past can be established only if a definite scale of time is accepted such that the first event would imply the absolute beginning of this very scale assuming that the passage of time to this beginning is qualitatively similar to the passage of time perceived as its linear flow. If, however, the scale of time in order to approach its beginning is different and is based on a different type of the limiting procedure, the very definition of the inaugural event as the first event becomes problematic. In this case the temporal finitude of the world is not incompatible with the inability to pin down the first event. Conversely, if the same alternative scale of the passage of time involves an infinite number of steps to accomplish it whilst remaining in the finite limits of the linear perception of time, one still can talk about not the first event of counting time through the infinite number of steps, but about the inaugural event of the very "beginning" of the count of time not in a pre-existing temporal sense, but as emerging logically as a philosophically understood event escaping the causality and any categorical predetermination.

In order to illustrate the last thought one can consider, as an example, the sequence of rational fractions of the type $\mathrm{P} / \mathrm{Q}$ (where $\mathrm{P}$ and $\mathrm{Q}$ interges) ascending in the order of magnitude, let us say, to the value of 1 . Let us associate this sequence with the passage of time from allegedly existing beginning at $\mathrm{t}=0$ (corresponding to the $\mathrm{lim}$ $\mathrm{P}_{\mathrm{n}} / \mathrm{Q}_{\mathrm{n}} \rightarrow 0$ ) to the present which is symbolized by $\mathrm{P} / \mathrm{Q}=1$. Such a sequence $\left\{\mathrm{P}_{\mathrm{n}} / \mathrm{Q}_{\mathrm{n}}\right\}$, 
whose concluding term is 1 , does have no first term as $\mathrm{Q}_{\mathrm{n}} \rightarrow \infty$ discretely reaching it only asymptotically, so that the smallest fraction effectively does not exist. However one can definitely say that the segment $(0,1]$ is of finite length. This is tantamount to the position of the world in some pre-existing entity which implies the transcendence of the world (as an exit from the rational sequence to the real) and thus positioning the whole sequence of counts within the segment as an object. According to this analogy the world history had no first term and yet the duration backwards from the present is finite. In respect to Kant's antinomies this example, although it can be taken only as an analogy, shows that the duration of the world backwards in time can be understood by two different means. The first one is a view that the world's age can be calculated only from within counting the sequence of time towards the past discretely by a sort of a limiting procedure. Then its duration is infinite because of the infinite number of terms in the temporal sequence or infinite numbers of steps in order to perform this sequence through computation. In this case the infinitude of the temporal passage of time is associated with its effective non-computability: in order to explicate the beginning of time one implies an infinite computational synthesis which is not available to the finite human being. However, if one models the temporality of the world on the grounds of the laws of physics by extrapolating them backwards in time as a formal parameter in the continuous differential equations, the age of the world (corresponding in our example to the segment $(0,1])$ could be finite, so that the "zero" $(0)$ can be treated as the first or inaugural event. One sees in these two cases in the representation of the beginning of the world an interesting overlapping of the issue of the inaugural event and the temporal finitude/infinitude of the world. If the approach to the modelling of the past implies the infinite number of computations, the world is infinitely old in the sense of non-computability, that is inexplicability in finite time. Correspondingly one cannot talk of the first event transferring the sense of the inaugural eventness of the world towards the inaugural eventness of the very process of computation. If the approach to the modelling of the past of the world is based on a finite computation of solutions of continuous differential equations, one comes to the explicit notion of the first instant of the physical world and this manifests the end of the method of physics as applicable to the world, thus explicating the finite nature of humanity who created this physics. The difference between these two approaches can be understood as if the opposite procedures in calculation of time sequences applied either exceptionally to the world as it is seen from within (the sequence of rational fractions which cannot be transcended into the realm of real numbers), or from the perspective of temporality 
transcending the limits of it sequential representation and thus having an abstract, intelligible sense. But in this case the inaugural event of the world turns out to be inextricably linked to the inaugural event of consciousness asserting such an event. Having no experience of one's own absolute beginning human beings struggle with defining such beginnings in the world. ${ }^{1}$

One can rearticulate the sense of what is implied in the question "Why did the world begin when it did?" (as a variation of the question "Why not sooner?") by making a clear distinction whether this question is posed from within an external or internal perspective. If this question is asked as if the world is considered within the process or series of events in it, then the implied question on the time at which this process began implicitly relates this process to some external temporal framework in relation to which the question of the beginning has sense. It is also implied here another dimension of the same question as related to the condition (external) for this worldly process to begin. However it is exactly the positioning of the world in external time or conditioning it that is impossible because, in coherence with longstanding theological arguments, there were no external relation to anything before the world. Unlike historical events that could have some preconditions for their happening, the world as a whole has nothing external to its history and hence its beginning. As was emphasised by Strawson, the supposition that it might have begun at some other time is as empty of meaning as the supposition that its external temporal relations might have been different (Strawson, 2006: 179). Correspondingly there cannot be any explanation as to "Why did the world begin when it did?" and not at some other time. However Strawson himself makes an attempt to elucidate the question concerned by modifying the sense of interrogation of the arbitrariness of the beginning of the world invoking the notion of the present now. Indeed, it is by attempting to conceive the history of the world as differently positioned in time, shifted either backwards or forwards, what is tacitly supposed is that all temporal relations in the world remain intact and the identity of the present moment remains independent of how time was filled in with historical events. In this sense the very shift of the whole sequence of the world events does not have any sense since it does not change anything in perception of the now.

This was emphatically expressed in the beginning of the $20^{\text {th }}$ century by Gabriel Marcel: "I cannot really stand aside from the universe, even in thought. Only by a meaningless pretence can I place myself at some vague point outside it, and from thence reproduce on a small scale the successive stages of its genesis. Nor can I place myself outside myself... and question myself upon my own genesis. I mean of course the genesis of my non-empirical, or metaphysical reality. The problem of the genesis of the I and of the genesis of the universe are just one and the same problem, or, more exactly, one and the same insoluble, the insolubility being bound up with my very position, my existence, and the radical metaphysical fact of that existence" (Marcel, 1965: 15). 
The question "Why did the world begin when it did?" can acquire a different sense if it refers to the internal nature of the world processes. In response to Strawson's claim that he does not know how this can be shown, and to his appeal for physicists to construe and answer this question as an internal question, modern cosmology can clarify some points. For example, the age of the universe is claimed to be between 13 and 14 billion years and one could ask the question, for example, why the universe needed so long to exist? Why its age is not, let say 13 or 14 millions (instead of billions) years? In this case cosmology gives quite an impressive justification that the universe must be older than 10 billion years in order the carbon-based life in the universe could develop and the human interrogation of the age of the world would be possible. However in this case the initial question on "Why did the world begin when it did?" has nothing to do with the allegedly existing or not empty (Absolute) space and time. Cosmology in this sense manifests itself as the science of immanence with no recourse to transcending the world. It has to accept that the age of the world is related to the initial conditions of this universe which, as such, are not controlled by the immanent physics. Certainly here is a teleological solution of the problem is possible relating the age of the universe to the necessary conditions for existence of the human intelligence. But in any case the asking of the question "Why did the world begin when it did?" implying a sort of external, transcendent, framework for the world is devoid of sense, for either theologically there is nothing beyond the world in terms of time and space, or, if one attempts to position the world "within eternity and infinity", there is no sense of asking "when" and "where" within them.

If, from what we have discussed, the external perspective for the question "Why did the world begin when it did?" does not have any sense, the internal perspective, in view of modern cosmology, reduces to the issue of initial conditions of the universe (in technical physical terms) or, more generally, to the problem of the inaugural event. The status of this event becomes a major concern of modern cosmology to the same extent as it was at the heart of the First antinomy: "The question of finite or infinite duration backwards from the present seem to be of interest only in so far as an answer to it carries with it one or other of the alternatives, a first event or no first event".

The thesis of Kant's antinomy contains a part related to spatial extension of the world: if the world is finite in time and had a beginning, its spatial span is also finite.

\footnotetext{
This what is known as the Anthropic Principle in cosmology, stating a fgine-tuned connection between the necessary conditions of the human existence and large-scale parameters of the universe. See, in this respect (Barow, Tipler, 1988: 18).

2 This was the assertion of (Broad, 1954-1955: 9).
} 
Kant's refutation of this thesis begins in the same way as he was refuting the thesis about time. If the spatial extension of the world is finite, this world must be situated somewhere within an unlimited empty space. It is reasonable to suggest that empty space implies here a sort of pre-existed reality, Absolute Space of a Newtonian kind, for example. Here Kant could potentially build his further argument by invoking the same move as he used with respect to the refusal of the beginning of time, namely that the position of the world in empty space cannot be fixed by any means, that is there is no sufficient reason for why the world could not be in another region of absolute space rather than to be where it is. In other words, if the world, if it exists, could be presented in the phenomenality of objects, it could be positioned in any part of the underlying absolute space and one cannot give any reason for a particular choice. One sees that this possible move would be similar to asking on the position of the beginning of the world on the scale of pre-existing time in the context of the question "Why not sooner?" related to the creation of the world in the inaugural event.

However, Kant invokes here a different argument which will allow us to reinterpret the question of "Why not sooner?" in a completely new perspective. According to him there must be a certain relation between the world as a whole and empty space in which this world is "situated". Kant describes this possible relation as a relation to nothing, concluding that there is no relation at all and thus the world cannot be limited in spatial extension. However his identification of empty space (or Absolute Space) with nothing must be clarified. Kant's identifying empty space with nothing can have sense only if he believes that empty space cannot be described in terms of those rubrics of thought which pertain to the world. In this case the very initial positioning of the finite world within nothing does not have any sense. If, on the contrary, empty space (Absolute Space) allows its presentation in abstraction, its relation to the world would not be a relation of nothing to something. One could agree that Absolute Space cannot be described as a thing, so that no relation is possible with respect to it as the relation of something (like the world) to another thing (which Absolute Space is not). In both cases it seems that what Kant tacitly implies in his invocation of nothing as a different name of Absolute Space is that the latter represents a non-material existent, that is a sort of intelligible entity whose ontological status is fundamentally different in comparison with that one of the world. This can be confirmed by Kant himself when he reaffirms that space is merely the form of outer intuition and that it is not a real object which can be outwardly intuited. "Space, ....is, under the name of absolute space, nothing but the mere possibility of outer appearances..." (Kant, footnote $b$ to B457: 398). In this 
case the very attempt to construct the relation between the world and Absolute Space understood in a non-material sense is a failure from the beginning since it attempts to bring into correlation two ontologically disconnected realms. Then the question of the arbitrary "position" of the world as a whole within Absolute Space, which is tantamount to the assertion that this Absolute Space is either geometrically (if it is thought as Euclidian space) or intelligibly uniform, becomes also a question of a definite size of the world which could be formulated similarly to that one on time: "Why not bigger or smaller?" This question is similar to the question about the contingent position of the world in Absolute Space for the size of the world cannot be measured in relation to the infinite absolute space and it can have, according to the fourth axiom of Euclid, any spatial measure. Certainly the question about the contingency of the world's size and its position in pre-existing Absolute Space has sense only if this Absolute Space is treated to be infinite in the sense of indefinite. When Kant appeals to it as the form of outer intuition, the infinity is implied as quantitatively indeterminant. In other words, if Absolute Space is treated as non-material "entity", being for example an intuitive form of the empirically impossible successive synthesis of the overall space of the universe, it deprives the thesis of Kant's antinomy of any ontological meaning and reasonability by converting thus into the statement of contingency of the world and impossibility of finding of any underlying cause for its facticity. If Absolute Space is treated as a form of outer intuition, then the very positioning of the world as a whole "inside" this form in the thesis of the antinomy is tantamount to representing the world as a whole as a finite object. Then the refutation of the thesis can be treated as the overcoming of the tension between the sense of the world as an event in the function of consciousness of Absolute Space on the one hand, and the sense of the world as an object in Absolute Space (that which is posited by consciousness as ontologically uniform with the world). The net result of the analysis of Kant's first antinomy is that the very intuition of the pre-existing space and time has strictly intelligible nature. Neither pre-existing time or space can be assigned an ontological status similar to that of the world. Correspondingly the positioning of the world in the background of preexisting conditions has only a propedeutic sense by disguising the perennial questions about contingent facticity of the world in terms of its age and its size.

All arguments on the dubious nature of positioning the world in Absolute Space can easily be applied to the positioning of the universe in "empty time", or eternity. In analogy with a spatial aspects of the world and Absolute Space any positioning of the world within eternity is an illusion of positioning the empirical world "within" 
the intelligible eternity. Once again we observe an inherent dualism present behind all Kantian arguments for explicating antinomies, namely the dualism between the sensible and intelligible. However Kant's position is not prone to a Platonic dualism, ontologizing the realm of the Absolute Space or eternity. His argument ultimately comes from his transcendental idealism portraying space and time as forms of sensibility with no ontological correlates. If things in space and time are only appearances, neither spatial nor temporal series which are presented in antinomies exist either as a limited or as an infinite totality as if these totalities could acquire the phenomenality of objects. In this sense the antinomies vindicate the thesis of transcendental idealism that contains the solution of the apparent conflict of reason with itself simply because they demonstrate exactly that the world as a whole cannot be subjected to the description in terms of quality, quantity, relation and modality, that is to be an/the object. Strawson gave three possible interpretations of Kant's solution to the problem of antinomies, each corresponding to a different version of transcendental idealism. All these versions contribute in a way to our stance on the impossibility of representation of the universe as a whole in the phenomenality of objects (Strawson, 2006: 187-197). However we want to dwell on one of his version, which, in the context of the question "Why not sooner?" brings us closer to that understanding of this problem as it was anticipated by St. Augustine.

If one takes a strong stance on transcendental idealism that nothing exists but temporally ordered perceptions, representations, experiences and inner determinations of the mind, and that the latter are attained in "themselves", it is reasonable to raise a question analogous to that considered in the first antinomy regarded the previous history of the allegedly existing world. Namely, whether the series of perceptions (inner determinations) has a beginning or stretches infinitely backward in time. It is evident that the question from the antinomy was not exactly about this. It concerned with the previous phases of the history of the universe in general, but not that particular subclass of events in this history, that is series of conscious experience of human beings. Correspondingly, if the beginning of the universe is portrayed through the series of perceptions of conscious beings, can one claim that somehow the representation of the beginning of the world correlates with the beginning of the series of perception? The response to the issue of the beginning of the world could be based on the reference considered above that one cannot ground any response in something which could not ever complete a survey of the universe as a whole in space and in time. This conclusion is based on the assumption that the conscious being is still capable of inferring either 
to the finitude or infinity of the world regardless of the a-priori unclarified structure of the very subjectivity which make enquiry into such a matter. This argument, in a way similar to that which we advocate by insisting that the universe (not saying at all of Absolute Space and eternity), or the world as a whole, cannot be presented in the phenomenality of objects.

\section{Creation out of nothing in the phenomenality of events}

The phenomenological refutation of the question "Why not sooner?" with respect to creation out of nothing leads us to the conclusion that neither the very act of creation or the created world as such can be subjected to relational analysis because it is unique and one cannot rerun the universe or stage it as an experimental event. Creation, or the universe as a whole is identical only to itself, so that its unfolding facticity is characterised not only by irreproducibility but by irreversibility understood not in a technical, thermodynamic sense, but as a logical irreversibility, as coming into the facticity of existence and the impossibility of exiting this existence. Creation makes itself a phenomenon not arising from our initiative and not responding to our expectations (since it cannot be reproduced). It gives itself to us from its own self to such an extent that it affects us, changes us and almost constitutes us, and stages us out of its own giving itself to us: hence it has a phenomenality of an event. ${ }^{1}$

The observation that creation (the universe as a whole) cannot be foreseen on the grounds of any causation, can be rephrased as that the universe imposes itself on perception without one being able to assign to it a substance in which it dwells as an accident (or a cause from which it results as an effect: there is no causal principle of the world). One could refer to the invisible whole of the universe as that substance "in" which the observable part of the universe (as its accident) dwells. The universe is given to us in its pieces and moments which represent that whole which will never be accessible per se. The invocation of the idea of the primordial substance in this context would just mean a conviction that there is an undifferentiated unity of "all in all", and the visible universe represents its particular realization of the demiurgic order out of chaos in the ancient sense. This mental split in the representation of the universe as substance and accident does not correspond however to the immediate experience of the universe as an event of life for it is in this event that it is exactly impossible to make a distinction between "substance" of life and life as an "accident". Correspondingly

More detailed description of the phenomenality of events can be found in (Marion, 2010: 244-308); see also (Romano, 1998; 2010). 
it is problematic to look for the cause of the universe (as the effect of this cause) if it is perceived as coaevus universo, that is the universe as "simultaneous" with one's life. The question of the facticity of the universe (as an effect of some cause) cannot be even addressed if the universe is seen as the totality of all. All rhetoric about the origination of the universe in the Big Bang has no philosophical significance as the "cause" of the universe, because it does not address the issue of the "cause" of the Big Bang itself. One can suggest that another typical characteristic of the universe as an event amounts to the fact that the number of "possible explanations" of its facticity is indefinite and increases in proportion to cosmological hermeneutics that cosmologists and their interpreters produce.

The treatment of the universe in the phenomenality of events does not deny its temporality. The temporality of the universe as a whole cannot be that of the physical flow in pre-existing time, it is a different temporality of events which must be elucidated. In order to do this let us start from a simple question: if the phenomenon of the universe giving itself in a mode of an event carries the signs of temporality, does it reaffirm the Kantian position that every phenomenon is a phenomenon if it admits a representation as experience in time-form of sensibility? The response to this is that while in Kant's view temporality serves only to allow the synthesis of phenomena as object with a certain identity, that is a guarantee of its permanence in presence justified through assigning it a cause or a reason, the event-like character of the universe as a whole cannot rely on this kind of a synthesis and thus permits a corresponding phenomenality of the universe contrary to the objectivity established in physical cosmology. The objectiveness of the created universe as permanence in presence through its evolution becomes a projection or even an illusion of an a-temporal event. The universe being described by mathematical laws as an evolving object entails that its notion is emptied of any intuitive content and thus represents a shadow of that event which gives itself in the fact of life. But then there is a question of the internal sense of temporality of life itself. Indeed, temporality belongs to sensibility of subjects articulating the universe and orienting them towards the synthesis of the already given objects. However it is this same temporality that is never applied in order to constitute and define the acting agent of this synthesis, that is the transcendental "I". Then, if one conjectures that the phenomena temporalized as objects (the evolving universe) preserve a trace of their belonging to the event (an intuition of the universe as a whole), still the transcendental "I" does not phenomenalize itself as an event. This happens because the "I" never phenomenalises itself at all: it does not appear among other phenomena, that is it 
is excluded from that phenomenality which it produces. In this sense the idea that the universe as a whole is an event seems to be counter-intuitive: indeed even if the "I" experiences their communion with the universe through the a-temporal, that is non-temporalizable sense of belonging and consubstantiality, any attempt to express this linguistically and discursively puts the event-like sense of communion under the rubrics of eidetic temporality. There is one particular aspect in the phenomenality of the universe which employs such an eidetic temporality, namely the universe's "beginning", its point of origination, the Big Bang. It is here that the universe is explicitly eidetically temporalized as an event. And this happens not accidentally, but because of a deep analogy between the Big Bang (as a shorthand notation for the temporal boundary of the universe) and an event of birth of any particular "I" which is the ultimate beginning and end of all possible predications of life as well as the universe. It is here that the "I" phenomenalises the universe as an event on the same grounds as it phenomenolizes itself as its own event of birth.

The origin of the universe which contains human beings appears in fact as a privileged phenomenon since a significant effort of humanity is devoted to its reconstitution as restoration of the lost memory of it, to giving it sense and even in a way responding to its appeal to us as if the universe had its distinctive self-identity. Still, humanity cannot see this undeniable and unavoidable phenomenon directly. The fact that one cannot see the origin of the universe directly and that nevertheless it reveals itself as a phenomenon for which cosmology constantly intends, constitutes an aporia which can be formulated in the following way: the origin of the universe shows to humanity precisely that its origin cannot be shown. This aporia urges a philosophising cosmologists to understand how the phenomenon of the origin of the universe that does not show itself directly not only affects humanity as if it did show itself, but, in fact, affects humanity in a more radical way than any other phenomena, since the beginning of the universe forms the necessary conditions for humanity's emergence in the universe. The same cosmologists have to admit that since this indemonstrable origin of the universe reveals itself to them, it "happens" to them in that it endows human beings with a future. The origin of the universe can be called a phenomenon because of its presence in absence, that is the poverty of demonstrability, so that it comes to pass in human life as an event, which was never present in presence, and is always already gone past, whereas it never surpasses the present and, in fact, is always to come. Thus one can say that the origin of the universe phenomenalises itself but as a pure event unpredictable (there is no sense of temporality before and outside the universe), irreproducible (one cannot 
rerun the universe), exceeding all cause (there is no physical causation from beyond the universe) and making the impossible possible (the probability of origination of our universe in multiverse scenarios is always infinitely small, that is the universe is a-priori impossible), surpassing all expectations and predictions (the constant advance of knowledge of the universe does not make it possible to assign to the universe some definitive and stable features which could sustain indefinitely the observational tests as well as an epistemological advance). Speaking of the origin of the universe we speak of its donation: it is given to us in the measure as it gives itself and its givenness to us is an apodictic fact-event which is alone responsible for that which we call the constituted phenomenon of the origin of the universe, or the universe as a whole. It is this givenness that initiates an encapsulated temporality of the universe as an event, which being projected onto the object-like temporality manifests the features of a shadow of the universe's wholeness and its non-originary origin.

By reiterating, the universe acquires the character of an event, that is a phenomenon that is unforeseeable on the basis of the past, incomprehensible on the basis of the present and irreproducible on the basis of the future. Cosmology attempts to reconstruct the invisible past of the universe on the basis of its present. In this sense the past of the universe is not "the past in the past" but rather "the past of the present", so that the unforeseeable future is simply a result of the fact that we do not know the past. However, neither is the universe exhaustively comprehensible on the basis of the present: the contingency of our location in space and time, as well as the contingency of the very factual self-articulation of the universe through the human voice, point towards the incommensurability (not consubstantiality) of the universe as a whole with its particular articulated incarnation leading to the untestability of many conjectures about the universe and the fundamental uncertainty of cosmology (See, e.g., (Ellis, 2007: 1220)). The universe is an event because it is not reproducible on the basis of the future: there is simply no future with respect to the universe as a whole which by definition incorporates all past, present and future. Finally one asserts that the universe, by definition, is a unique occurrence, it is that which has a modality of absoluteness. All cosmological theories which attempt to explore the possibility of non-uniqueness of this universe ${ }^{1}$ make a reduction of the phenomenality of this universe to that distorted and damaged phenomenality which is typical of objects constituted by the empirical sciences, the phenomenality which is poor in intuition (foreseeable as reconstructed

See on the multiverse hypothesis (Carr, 2007). 
from the allegedly existing past, exhaustively knowable according to existing theories, reproducible theoretically through the plurality of different scenarios). It is clear that what is left behind these reconstructions is a historical dimension of the universe as a unique and contingent event which cannot be exhausted by its reduction to human subjectivity, in particular to that mode which deals with the universe's thematization as an object. Here the historicity of the universe is understood not as a sequence of its stages of evolution as they are described in cosmology. One implies the historicity of the universe as a whole as its contingent givenness to humanity in its entire span of time and space, that is as a humanly historical relation and communion. This historicity has a different origin, following not from physical causality but rather originating in intentional consciousness as the intrinsic and mysterious unity of subject and object, being and non-being, spirit and matter.

\section{Conclusion}

By using historical examples of the Christian Patristics and Kant's transcendental philosophy we have demonstrated that any philosophical approach to the issue of origin of the world made in the natural attitude is unsustainable. This entailed that the representation of the origin of the universe in the phenomenality of object fails. Then it was suggested that all historical examples pointed towards placing the issue of origin of the universe within the modern phenomenological discourse of phenomenality of events as unpredictable and irreproducible happening, exceeding all cause and making the impossible possible, surpassing all expectations and predictions.

\section{References}

Augustine (1980). Civitate Dei. ET: The City of God, tr. H. Bettenson. New York: Penguin Books.

Augustine (1991). Confessiones. ET: H. Chadwick (tr.). Augustine's Confessions. Oxford University Press.

Balthasar, H.U. von (2003). Cosmic Liturgy. The Universe according to Maximus the Confessor. San Francisco: Ignatius Press.

Barow, J.D., Tipler, F.J. (1988). The Anthropic Cosmological Principle. Oxford UP.

Basil the Great (1984). The Hexaemeron. ET: The Nicene and Post-Nicene Fathers, 8. Grand Rapids, MI: W. B. Eerdman Publishing Company.

Blowers P.M., Wilken R.L. (2003). On the Cosmic Mystery of Jesus Christ, Selected Writings from St. Maximus the Confessor. Crestwood: St. Vladimir's Seminary Press. 
Broad, C.D. (1954-1955) “Kant's Mathematical Antinomies”, In Proceedings of the Aristotelian Society 55, 9.

Carr, B.J. (ed.) (2007). Universe or Multiverse. Cambridge: Cambridge University Press.

Clément, O. (1976). Le Christ Terre des Vivants. Essais Théologiques. Spiritualite Orientale, n. 17. Bégrolles-en-Mauges: Abbaye de Bellfontaine.

Ellis, G.F.R. (2007). "Issues in the Philosophy of Cosmology", In Handbook of the Philosophy of Science, Philosophy of Physics. Part B, ed. J. Butterfield, J. Earman. Amsterdam et al: Elsevier, 1183-1283.

Kant, I. (1933). Critique of Pure Reason. Trans. N. K. Smith. London: Macmillan.

Louth, A. (1996). Maximus the Confessor. London: Routledge.

Marcel, G. (1965). Being and Having. London: Collins.

Marion, J.-L. (2010). Certitudes negatives. Paris, Bernard Grasset.

Natanson, M. (1959). “Being-in-Realty”, In Philosophy and Phenomenological Research 20, (2), 231-237.

Nesteruk, A. (2012). "The Origin of the Universe and Event of Birth: Phenomenological Parallels", In J. Sib. Fed. Univ. Humanit. soc. sci., 5(2), 172-205.

Nesteruk, A. (2014). "The Universe as a Saturated Phenomenon: The Christian Concept of Creation in View of Modern Philosophical and Scientific Developments", In Theology and Science, 12(3), 236-259.

Nesteruk, A. (2015). The Sense of the Universe. Philosophical Explication of Theological Commitment in Cosmology. Minneapolis: Fortress Press.

Penrose, R. (2005). The Road to Reality. London: Vintage Books.

Romano, C. (1998). L'événement et le monde. Paris: Presses Universitaires de France.

Romano, C. (2010). L'aventure temporelle. Trois essais pour introduire à l'herméneutique événementiale. Paris: Presses Universitaires de France.

Sherwood, P. (1955). St. Maximus the Confessor. The Ascetic Life. The Four Centuries on Charity. London: Longmans.

Sorabji, R. (1983). Time, Creation and the Continuum (theories in antiquity and the early middle ages). London: Duckworth.

Sorabji, R. (1988). Matter, Space and Motion. Theories in Antiquity and Their Sequel. London: Duckworth.

Strawson, P.F. (2006). The Bounds of Sense. An Essay on Kant's Critique of Pure Reason. London: Routledge. 
Thunberg, L. (1995). Microcosm and Mediator: The Theological Anthropology of Maximus the Confessor. Chicago: Open Court.

Tryon, E. (1998). "Is the Universe a Vacuum Fluctuation?", In. J. Leslie, Ed., Modern Cosmology and Philosophy. Prometheus Books, New York, 222-225.

\title{
Феноменологическая интерпретация сотворения мира из ничего: \\ от патристики до Канта и современности
}

\author{
А.В. Нестерук ${ }^{\mathrm{a}}$, Т.В. Литвин ${ }^{\tilde{\sigma}, \mathrm{B}}$ \\ ${ }^{a}$ Университет Портсмута \\ Великобритания, Портсмут, РО1 3НF, Лайон Гэйт Бюлдинг \\ ${ }^{6}$ Национальный научный фонд Греичии \\ Греиия, 11635, Aфины, ул. Vassileos Constantinou, 38 \\ ${ }^{8}$ Русская христианская гуманитарная академия \\ Россия, 191011, Санкт-Петербург, наб. реки Фонтанки, 15
}

В статье рассматривается одна из вечных проблем философии о причинном приниипе мира, в частности, проблема его сотворения так, как она понимается в христианском богословии. Развивается мысль о том, что представление сотворения мира невозможно в естественной установке сознания, m. е. в феноменальности объектов. Поскольку описание сотворения выходит за рамки классической метафизики, естественно предположить, что оно может быть описано в феноменальности событий. Мы демонстрируем это, рассматривая примеры из патристики в контексте возражений воззрению о сотворении мира из ничего, основанном на аргументе, получившем в истории название "Почему не раньше?» Показано, что Отцыь Церкви предвидели невозможность трактовки сотворения в феноменальности объектов и неявно трактовали сотворение как насыщенный феномен, феноменальность которого носит событийный характер. Далее производится анализ первой космологической антиномии Канта с иелью получить еще одно свидетельство в пользу того, что начало мира не может быть интерпретировано в феноменальности объектов. В заключительной части нами сформулирован тезис, что Вселенная в иеелом, как и ее основание (начало), могут быть поняты только как непредсказуемое и невоспроизводимое событие, выходящее за рамки причинности и манифестирующее возможность невозможного.

Ключевые слова: богословие, космология, сотворение, христианство, событие, онтология, феноменальность, философия, время.

Научная специальность: 09.00.00 - философские науки. 